\title{
Discounted Cash Flow (DCF) as a Measure of Startup Financial Success
}

\author{
Erkki K. Laitinen \\ The School of Accounting and Finance, University of Vaasa, Vaasa, Finland \\ Email: erkki.k.laitinen@uwasa.fi
}

How to cite this paper: Laitinen, E.K. (2019) Discounted Cash Flow (DCF) as a Measure of Startup Financial Success. Theoretical Economics Letters, 9, 2997-3020. https://doi.org/10.4236/tel.2019.98185

Received: November 8, 2019

Accepted: December 23, 2019

Published: December 26, 2019

Copyright $\odot 2019$ by author(s) and Scientific Research Publishing Inc. This work is licensed under the Creative Commons Attribution International License (CC BY 4.0).

http://creativecommons.org/licenses/by/4.0/ (c) (i) Open Access

\begin{abstract}
The purpose of the study is to investigate the characteristics of the discounted cash flow (DCF) as a measure of startup financial success. In general, DCF is found the most popular method in startup valuation followed by the internal rate of return (IRR) and the payback period methods. However, the consequences of using this method in startup valuation are rarely analyzed in financial research. In this study, a simplified mathematical model is developed to describe the time-series development of the cash flow. This model is based on the growth of expenditures and their ability to generate revenues from the founding of the startup. The model employs IRR as the measure of true profitability and the average lagin revenue generation as a proxy of the payback period. Numerical experiments are used to show the sensitivity of DCF to the parameters of the model. The results indicate that the use of DCF favors startups that grow slowly and have a short payback period but that also exhibit a high IRR. The longer the time series of the startup used in the analysis, the more significant role IRR tends to play in DCF. Empirical evidence extracted from a sample of Finnish startups supports the numerical findings.
\end{abstract}

\section{Keywords}

Discounted Cash Flow, Startup, Profitability, Growth, Payback Period, Risk Aversion

\section{Introduction}

The success of startups is important for economies investing on innovations and growth. Therefore, especially the early years of startups have been popular themes of business research, literature, and government policy debate [1]. Startups are necessary for the creative destruction process as they enter the market and replace old and stagnant firms [2]. However, this process is potentially com- 
plicated since startups typically have insufficient financial resources to follow their plans for the early years. Startups are often faced by difficulties to raise equity or debt finance and are therefore forced to rely heavily on internal finance. Zingales [3] in fact regards internal finance as the main source of financial capital for startups. The determinants of the sufficiency of this finance are related to the early-stage growth and profitability of startups. Therefore, it is important to the investors, financers, and entrepreneurs that the determinants of internal finance in the early years of startups are well understood.

Internal finance is based on the cash flow generated by the startup. Therefore, cash flow is a significant indicator of a startup facing financial constraints. Startups with strong cash flows continue to operate and grow, while startups with weak cash-flow close and eventually die [2]. It is often suggested that highly cash-flow sensitive firms are those facing the least constraints [4]. Some researchers further argue that cash flows reveal information about investment quality [5]. Cash flow is not connected with the characteristics of financial reporting as strongly as accrual flows. This is important, since one of the objectives of financial reporting is to make managers and entrepreneurs accountable to investors so that there is efficient allocation of capital. The most efficient firms should receive financing and have higher valuations, than worse firms [6]. For mature firms living in steady conditions and generating predictable cash flows, investors can generally agree with their value. However, in the early stages startups typically suffer from unstable development making the valuation for an external investor very challenging.

Because of the importance of cash flows for the development of startups, valuation methods based on the discounted cash flow (DCF) are recommended by prior studies [7]. DCF is also the most commonly used valuation method employed by investors [8] [9] [10]. Especially, DCF is the preferred method when there is little information available to compare with. That is the reason why DCF is the method most widely used in startups that typically have lower income and high growth expectations. Reverte, Sánchez-Hernández \& Rojo-Ramírez [7] however emphasize that in using the DCF method to estimate the fair value of an investment, the investor should derive the present value of the investment, using reasonable assumptions and estimations of expected future cash flows and the terminal value, and the appropriate risk-adjusted rate that quantifies the risk inherent to the investment. It is clear that these important variables (cash flows, terminal value, and discount rate) require substantial subjective judgement to be made. This study does however not focus on these obvious estimation difficulties, which are well known to investors.

Thus, instead of concentrating on the estimation problems the objective of this study is to analyze the consequences (outcomes) of using DCF to assess time-series of startups. Therefore, the objective is here to investigate what kinds of startups are preferred to or neglected when using DCF in assessment. This means that the time-series of cash flow are in this study described using parameters that characterize the target startup in a relevant way. In reality, the 
time-series of startups are usually nonstationary [1] [11] [12] [13]. Prior studies generally indicate that the development of startups is non-linear and prone to interruptions and setbacks, which are stochastic and quite difficult to explain using different variables and processes [11]. However, to avoid these difficulties Laitinen [14] constructed a simplified model to explain the early development of financial ratios. He showed that in the early years of startups profitability ratios give a very unreliable estimate of the real profitability of the startup. In this study, a similar mathematical model is developed to depict the development of cash flow to be used to analyze DCF in a simplified framework.

In the present framework, the growth of expenditure in a startup is described by a steady growth model. Following the basic idea of identical investment projects, it is assumed that each periodic expenditure generates a proportionally identical infinite (geometric) flow of revenue. The profitability in terms of the internal rate of return (IRR) and the lag structure of revenue flows are assumed constant. In this framework, steady growth rate refers to the growth of the startup, IRR to the true profitability, and the lag structure parameter to the payback period of periodic investments. The behavior of the cash flow in this simple framework is analyzed using numerical experiments. In these experiments, the periodic revenue is assumed stochastic and a discount rate is used to calculate the present value of the cash flow to act as a surrogate of DCF. These experiments clearly show that the real profitability (IRR) is an important determinant of DCF. However, the use of DCF obviously prefers startups with a low growth rate and a short payback period to startups with a higher growth rate and a longer payback period. These conclusions are supported by empirical evidence extracted from Finnish startups. These kinds of consequences are not favorable for a valuation method, since it disregards high growth startups with long payback period. These characteristics are typical for high technology startups, which are essential for innovations and growth.

The content of the study is organized as follows. Firstly, the introductory section presented the motivation, objective, and contribution of the study that all are associated with the use of DCF to assess startups. Secondly, an analytical model of the time-series of cash flow is drawn up and analyzed in the second section. The purpose is to show how the model parameters endogenously affect the development of cash flow in the early years of a startup. The model is used to derive analytically the expected present value of the cash flow (DCF) but also the variance of DCF incorporating a simple stochastic variable in the model. The mean and variance of DCF are used to include risk aversion in the framework. Thirdly, the analytical results are used to build up numerical experiments to show the sensitivity of DCF to the parameters of the model. Fourthly, numerical results are presented and discussed in the fourth section. In this section, also empirical evidence from Finnish startups is used to assess the relevance of the numerical results. Finally, the last section discusses and concludes the main findings and limitations of the study and gives hints for future research on DCF. 


\section{Cash Flow Model}

The development of cash flow for a startup in the early years is a complicated and stochastic process [11]. Therefore, Reid [12] applied a dynamic theory to predict trajectories for key financial variables of a startup whereas Coad et al. [13] used Gambler's Ruin framework by arguing that startup performance is best modelled as a random walk process. In the present framework, a simplified set of assumptions are first applied to depict the development of cash flow under deterministic circumstances. Later, a simple stochastic process is incorporated in the model. In this framework, such aspects as continuing (terminal) value, depreciations and tax savings are excluded [15]. The framework is similar with the approaches used to explain the relationship between the accounting rate of return (ARR, ROI) and the internal rate of return (IRR) [14] [16] [17] [18] [19]. In these frameworks, growth plays an important role. For a startup, growth is critical for survival in the early stages, since new firms that do not grow are more likely to fail or close [11] [13]. It is assumed here that the entrepreneur periodically invests on the startup an expenditure that grows periodically at a steady rate [14]. Thus, the time series of periodic expenditure can be described as follows:

$$
M_{t}=M_{0}(1+g)^{t}
$$

where $M_{t}$ refers to expenditure spent in period $t$ and $g$ is the steady rate of growth $(g>0)$. For simplicity, random elements [13] are thus far neglected in this framework.

It is important for the survival of the startup that the business starts to generate revenue as quickly as possible after founding. In this way, the startup strengthens internal finance and ensures a successful entry to the market. Gilbert, McDougall \& Audretsch [20] review 48 empirical studies on new firm growth concluding that growth of sales revenue is one of the most important measures of growth. The present model assumes that the business process of the startup is proportionally fixed and repetitive so that periodic expenditure generates a similar but steadily growing flow of revenue beginning from the investment period. It is assumed that the lagged flow of revenue generated by periodic expenditure follows a geometric distribution, which leads to the following expression:

$$
\begin{aligned}
R_{t} & =K M_{0} \sum_{i=0}^{t}(1+g)^{i} q^{t-i}=K M_{t} q^{t} \sum_{i=0}^{t}(1+g)^{i} q^{-i} \\
& =K M_{t} \frac{(1+g)^{t+1}-q^{t+1}}{(1+g)^{t}(1+g-q)}
\end{aligned}
$$

where $K$ is the level parameter of the lagged revenue distribution whereas $q$ is the lag parameter describing the geometric lag structure. The lag parameter $q$ is defined as being greater than 0 but less than 1 .

Equation (2) shows that the resulted time series of revenue is a non-steady process where the growth path is largely determined by the difference between $g$ and $q$. In the early growth process the growth rate of revenue converges towards 
$g$ faster, the lower is $q$. When $n$ approaches the infinity, the growth rates of expenditure and revenue are equal and the startup lives in a steady state. If it is assumed that the lag distribution is infinite, IRR or $r$ can be incorporated in the model as follows:

$$
M_{t}=M_{t} K \sum_{i=0}^{\infty} q^{i}(1+r)^{-i} \geq K=\frac{1+r-1}{1+r}
$$

where $K$ is less than unity.

Each proportionally identical periodic expenditure generates a flow of revenue yielding the same IRR, which means that $r$ equals IRR also at the level of the firm. Thus, $r$ refers to the true or principal profitability of the startup. IRR is solely based on expenditure and revenue concepts and is therefore independent of expense concepts. In the present framework, the lag parameter $q$ is also an important concept being associated with the payback period of periodic expenditure investments. The payback period and IRR are popular assessment methods in capital budgeting and investing. The lag parameter tells how quickly invested expenditure generates revenue to the startup. The revenue lag is increasing in $q$ with the average lag defined as $q /(1-q)$ (weighted average of all lags) and with the median lag defined as $-\log 2 / \log q$ (time when $50 \%$ of revenue contributions are generated). However, the payback period of each identical project depends on IRR in addition to $q$. It can be presented as $\log (r /(1+r-q)) / \log q$. It shows the time when the accumulated revenue flow for the first time exceeds the periodic expenditure.

In this framework, the cash flow is defined as the difference between revenue and expenditure. Using Equation (2) the present value of the cash flow can be presented in the following form:

$$
\begin{aligned}
D C F_{t} & =\sum_{i=0}^{t}\left(R_{t}-M_{t}\right)(1+d)^{-i} \\
& =M_{0} \sum_{i=0}^{t}\left\{\frac{K\left[(1+g)^{i+1}-(1+g)^{i}\right]}{1+g-q}-(1+g)^{i}\right\}(1+d)^{-i}
\end{aligned}
$$

where $d$ is the rate of discount.

Solving the summation terms in Equation (4) and rearranging the terms leads to the following solution:

$$
\begin{aligned}
D C F_{t}= & M_{0}(1+d)\left\{\frac{1}{d-g}\left[\frac{(1+r-q)(1+g)}{(1+r)(1+g-q)}-1\right]\left[1-\left(\frac{1+g}{1+d}\right)^{t+1}\right]\right. \\
& \left.-\frac{q}{1+d-q}\left[1-\left(\frac{q}{1+d}\right)^{t+1}\right]\right\}
\end{aligned}
$$

where

$$
\frac{(1+r-q)(1+g)}{(1+r)(1+g-q)}=\frac{R_{t}}{M_{t}} t \rightarrow \infty
$$

Equation (6) depicts the steady state value of the revenue-expenditure ratio 
that exceeds unity if $r>g$ and equals unity if $r=g$. It is less than unity if $r<g$. Equation (5) shows that the effects of the parameters on $D C F_{t}$ are dependent on the length to $f$ the cash flow time-series. The marginal effect of IRR or $r$ on $D C F_{t}$ is positive. However, its effect can increase or decrease with the length of the time-series depending on the relation between $g$ and $d$ : if $g>d$, then the effect is increasing in $t$ and vice versa. Similarly, in that case, the effect of growth on $D C F_{t}$ is increasing in $t$, and decreasing in the opposite case. However, the marginal effect of $g$ is complicated and difficult to interpret. The effect of lag parameter $q$ on $D C F_{t}$ is decreasing with the length $t$ of the time series, since $q /(1+d)$ $<1$. If $r=g, D C F_{t}$ only depends on $M_{0}, q$ and $d$ through the second term of (5).

\section{Numerical Experimentation}

Equation (5) gives an insight of how the parameters of the present model affect the discounted value of cash flow or $D C F_{t}$. However, the intrinsic effects of parameters are complicated and difficult to assess analytically especially when the parameters change at the same time. Therefore, the interpretation of the results is here facilitated using numerical experimentation. This kind of experimentation makes it possible to include stochastic variables in the deterministic model. For a startup, the time series of sales are typically characterized by random chocks, which makes the cash flow to follow a stochastic process [11] [12] [13] [21]. Thus, it is assumed here that the periodic sales revenue does not realize according to the deterministic formula (2) but is in each period exposed to a random chock as described by the following equation:

$$
R_{t}=K M_{t} \frac{(1+g)^{t+1}-q^{t+1}}{(1+g)^{t}(1+g-q)} \cdot X(t)
$$

where $X(t)$ is a random variable that makes a proportional impact on $R_{t}$.

For simplicity, it is assumed that $X(t)$ follows a uniform distribution $U(a, b)$ with the minimum value $a$ and the maximum value $b$ which are constant for each period $t$. It is also symmetrically assumed that the expected value of the random variable is $\operatorname{MEAN}(X(t))=(a+b) / 2=1$ so that the expected value of $R_{t}$ equals to (2). The constant variance of the random variable $X(t)$ is $\operatorname{VAR}(X(t))=(b-a)^{2} / 12$ leading to the following variance of the discounted cash flow $D C F_{t}$ :

$$
\operatorname{VAR}\left(D C F_{t}\right)=\frac{K^{2} M_{0}^{2}}{(1+g-q)^{2}} \sum_{i=0}^{t}\left[\frac{(1+g)^{i+1}-q^{i+1}}{(1+d)^{i}}\right]^{2} \operatorname{VAR}(X(i))
$$

which is a quite complicated function of the parameters of the model. Equation (8) however indicates that the effect of $g$ is increasing and the effect of $q$ is decreasing in the number of period.

In the numerical experiments, each of the four model parameters $r, g, q$, and $d$ have three different representative values (low, average, high) so that the number of combinations of values is $3^{4}=81$ (cases). For each combination or case, 100 simulation runs were executed to randomize the analysis allowing $X(t)$ be de- 
termined in each period according to $U(a, b)$ which totally led to $81 \cdot 100=8100$ runs. Then, for each of the 81 randomized cases, the mean and the variance of $D C F_{t}$ were calculated. The robustness of the results was evaluated re-running the 8100 runs ten times and comparing the results got from every re-run. The results differed in these re-runs very little and did not lead to any changes in interpretation of the results. Table 1 presents the values of the parameters used in the experiments. Table 2 shows the payback period of the periodic projects for each combination of $q$ and $r$. The longest payback period is 6.23 years $(q=$ 0.75 and $r=0.05)$ whereas the shortest time is only 1.00 year $(q=0.25$ and $r=$ $0.25)$. The 8100 runs are calculated separately for startups with 5 - and 10-year time series $(N=5$ or 10$)$ to analyze the effect of the life cycle stage (respectively, launch and growth stages). Furthermore, the effect of risk in revenue generation on $D C F_{t}$ is assessed calculating the runs separately for a lower and a higher risk condition determined by $a$ and $b$.

The experiments provide us with four different outcome variables used in assessing the effects on $D C F_{t}$. Firstly, for each of the 81 cases the mean and, secondly, the variance of $D C F_{t}$ are numerically calculated over the 100 randomized observations. Thirdly, in order to assess the efficiency of a case in the set of the 81 cases (portfolio) it was calculated for each case how many of other 80 cases it dominates on the mean-variance relationship. Case $A$ is here said to dominate case $B$ if the mean of $D C F_{t}$ for $A$ is greater than or equal to that for $B$ and, at the same time, the variance of $D C F_{t}$ for $A$ is lower than or equal to that for $B$. The number of dominated cases is called here "dominance" and theoretically, it varies between $0-80$. Fourthly, following the mean-variance utility theory the weighted difference of the mean and the variance of $D C F_{t}$ that measures the expected utility of $D C F_{t}$ is calculated in the following form:

$$
E\left(u\left(D C F_{t}\right)\right)=\operatorname{MEAN}\left(D C F_{t}\right)-\frac{\lambda}{2} \cdot \operatorname{VAR}\left(D C F_{t}\right)
$$

where $\lambda$ is the rate of risk aversion. For investors, the values of risk aversion rate vary significantly in practice [22]. In Finland, the average rate for executives is slightly over unity allowing approximating utility by a logarithmic function [23]. Thus, three different levels of $\lambda$ are used in experimentation to show the effect of risk aversion (low 0.5; average 1.0; and high 1.5) and the average value is set equal to unity.

\section{Results of Experiments}

\subsection{Launch Stage}

Figure 1 presents graphically the resulted relationship between the mean and the variance of $D C F_{t}$ under lower risk circumstances ( $a=90$ and $\left.b=110\right)$ for the launch stage. This stage makes use of the five first years of the simulated startup to calculate $D C F_{t}(N=5)$. It is remarkable that all 81 cases have a negative mean of $D C F_{t}$ indicating how difficult the first years are for a startup even with a good IRR. Table 3 presents the cases with three highest and lowest values for the 
Table 1. Parameters of the model used in the experiments.

\begin{tabular}{|c|c|c|c|c|c|c|c|c|c|}
\hline \multirow[b]{2}{*}{$M_{0}$} & \multirow[b]{2}{*}{$r$} & \multirow[b]{2}{*}{$q$} & \multirow[b]{2}{*}{$g$} & \multirow[b]{2}{*}{$N$} & \multirow[b]{2}{*}{$d$} & \multicolumn{2}{|c|}{ Lower risk: } & \multicolumn{2}{|c|}{ Higher risk: } \\
\hline & & & & & & Lower limit & Upper limit & Lower limit & Upper limit \\
\hline 100 & 0.05 & 0.25 & 0.05 & 5 or 10 & 0.025 & 0.90 & 1.10 & 0.80 & 1.20 \\
\hline 100 & 0.15 & 0.50 & 0.15 & 5 or 10 & 0.050 & 0.90 & 1.10 & 0.80 & 1.20 \\
\hline 100 & 0.25 & 0.75 & 0.25 & 5 or 10 & 0.075 & 0.90 & 1.10 & 0.80 & 1.20 \\
\hline
\end{tabular}

Table 2. Payback period $t$ for different experimental values of $q$ and $r$.

\begin{tabular}{llllllllll}
\hline$q$ & 0.2500 & 0.5000 & 0.7500 & 0.2500 & 0.5000 & 0.7500 & 0.2500 & 0.5000 & 0.7500 \\
\hline$r$ & 0.0500 & 0.0500 & 0.0500 & 0.1500 & 0.1500 & 0.1500 & 0.2500 & 0.2500 & 0.2500 \\
$t$ & 2.0000 & 3.4594 & 6.2283 & 1.2925 & 2.1155 & 3.4094 & 1.0000 & 1.5850 & 2.4094 \\
\hline
\end{tabular}

Table 3. Highest and lowest values of the outcome variables for $N=5$ and $a=0.9 \& b$.

\begin{tabular}{|c|c|c|c|c|c|c|}
\hline & \multicolumn{2}{|c|}{ Highest value } & \multicolumn{4}{|c|}{ Lowest value } \\
\hline & 1. & 2. & 3. & 1. & 2. & 3. \\
\hline Mean & -0.76 & -2.82 & -4.69 & -434.10 & -407.96 & -385.94 \\
\hline$r$ & 0.250 & 0.250 & 0.250 & 0.050 & 0.050 & 0.050 \\
\hline$q$ & 0.250 & 0.250 & 0.250 & 0.750 & 0.750 & 0.750 \\
\hline$g$ & 0.050 & 0.050 & 0.050 & 0.250 & 0.250 & 0.250 \\
\hline$d$ & 0.025 & 0.050 & 0.075 & 0.025 & 0.050 & 0.075 \\
\hline Variance & 781.41 & 716.04 & 647.17 & 85.80 & 106.63 & 130.22 \\
\hline$r$ & 0.250 & 0.250 & 0.050 & 0.050 & 0.050 & 0.150 \\
\hline$q$ & 0.250 & 0.500 & 0.250 & 0.750 & 0.750 & 0.750 \\
\hline$g$ & 0.250 & 0.250 & 0.250 & 0.050 & 0.050 & 0.050 \\
\hline$d$ & 0.025 & 0.025 & 0.025 & 0.075 & 0.050 & 0.075 \\
\hline Dominance & 69 & 52 & 51 & 0 & 0 & 0 \\
\hline$r$ & 0.250 & 0.250 & 0.150 & 0.250 & 0.050 & 0.150 \\
\hline$q$ & 0.250 & 0.500 & 0.250 & 0.250 & 0.500 & 0.500 \\
\hline$g$ & 0.050 & 0.050 & 0.050 & 0.250 & 0.250 & 0.250 \\
\hline$d$ & 0.050 & 0.050 & 0.075 & 0.025 & 0.025 & 0.025 \\
\hline$\lambda=0.5$ & -45.12 & -61.40 & -62.35 & -507.07 & -466.11 & -434.64 \\
\hline$r$ & 0.250 & 0.250 & 0.250 & 0.050 & 0.050 & 0.050 \\
\hline$q$ & 0.250 & 0.250 & 0.250 & 0.750 & 0.750 & 0.750 \\
\hline$g$ & 0.050 & 0.050 & 0.050 & 0.250 & 0.250 & 0.250 \\
\hline$d$ & 0.050 & 0.075 & 0.025 & 0.025 & 0.050 & 0.075 \\
\hline$\lambda=1.0$ & -87.42 & -116.62 & -118.01 & -580.04 & -524.25 & -492.72 \\
\hline$r$ & 0.250 & 0.150 & 0.250 & 0.050 & 0.050 & 0.150 \\
\hline$q$ & 0.250 & 0.250 & 0.500 & 0.750 & 0.750 & 0.750 \\
\hline$g$ & 0.050 & 0.050 & 0.050 & 0.250 & 0.250 & 0.250 \\
\hline$d$ & 0.050 & 0.075 & 0.050 & 0.025 & 0.050 & 0.025 \\
\hline$\lambda=1.5$ & -129.73 & -165.41 & -166.15 & -653.02 & -633.25 & -616.55 \\
\hline$r$ & 0.250 & 0.050 & 0.150 & 0.050 & 0.250 & 0.250 \\
\hline$q$ & 0.250 & 0.250 & 0.250 & 0.750 & 0.750 & 0.500 \\
\hline$g$ & 0.050 & 0.050 & 0.050 & 0.250 & 0.250 & 0.250 \\
\hline$d$ & 0.050 & 0.075 & 0.075 & 0.025 & 0.025 & 0.025 \\
\hline
\end{tabular}




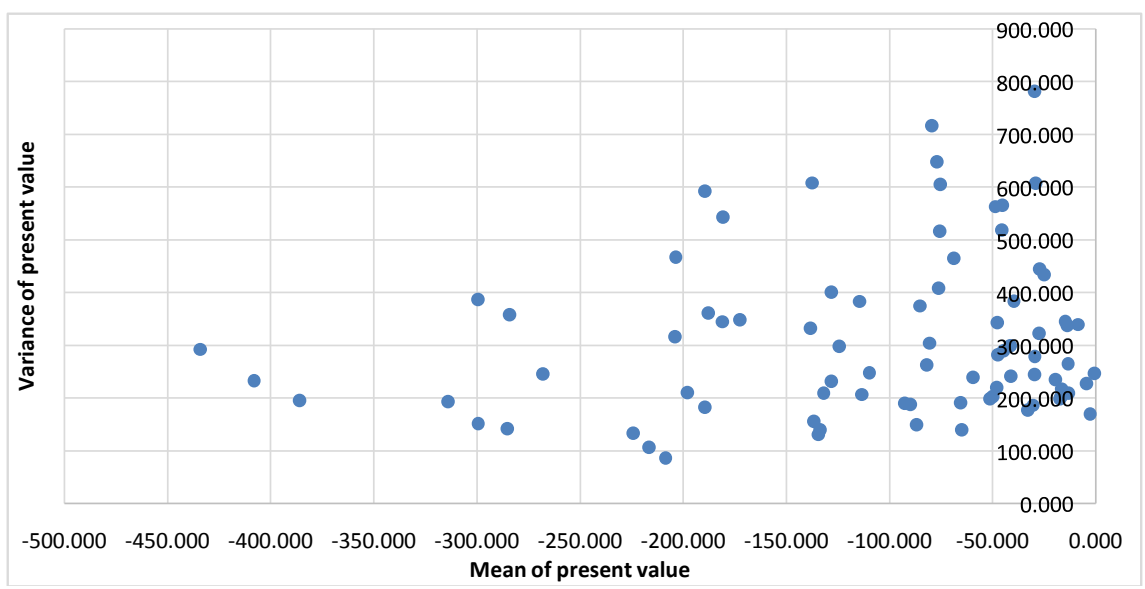

Figure 1. The relationship between the mean and the variance of DCF for $N=5$ and a $=$ $0.9 \& b=1.1$.

outcome variables. First, the highest values of the mean $D C F_{t}$ are associated with high $r$, low $q$, and low $g$ whereas the lowest values are related to high $q$ and high $g$. Secondly, the variance of $D C F_{t}$ is an increasing function of $g$ but a decreasing function of $q$. Third, dominance is strongly determined by $g$. the lower $g$, the higher is dominance. Fourth, the comparison of the outcome for different rates of risk aversion shows that the higher risk aversion, the higher are the negative effects of $q$ and $g$ in a relation to the effects of $r$.

The effect of the parameters is further analyzed using the ten cases with the highest values of the outcome variables (TOP 10). Panel of Table 4 shows that TOP 10 for the mean of $D C F_{t}$ includes eight cases with the highest value of $r$ (0.25), eight cases with the lowest value of $q(0.25)$, and seven cases with the lowest value of $g(0.05)$. Thus, the three parameters show a quite strong impact each, since if randomly distributed, TOP 10 only includes 3 - 4 such extreme values. For other four outcome variables, TOP 10 includes all ten cases with the lowest value of $g(0.05)$ except for the variance whose TOP 10 includes all ten cases with the highest value of $g(0.25)$. In TOP 10 for the variance, six cases with the highest value of $r(0.25)$ and five cases with the lowest value of $q$ are included. For the four other outcome variables, TOP ten includes five cases with the highest value of $r(0.25)$ and eight cases with the lowest value of $q(0.25)$ with an exception for the outcome variable of the highest risk aversion $(\lambda=1.5)$ with only six such cases. These analyses show the strong effects of $q$ and especially $g$ on the outcome variables. The mean of $D C F_{t}$ seems to be the only outcome variable that is strongly associated with $r$.

Table 5 presents the Spearman rank correlation coefficients between the outcome variables. These coefficients show that the outcomes of the three risk aversion rates are highly correlated with each other reflecting here a rather weak effect of aversion. Moreover, dominance is highly correlated with these outcomes. Table 6 presents the Spearman correlation coefficients between the parameters of the model and the outcome variables. It shows that $r$ is positively correlated 
Table 4. The contents of TOP 10 solutions for different outcome variables. (a) Panel 1. $N$ $=5, a=90, b=110$ (launch stage). (b) Panel 2. $\mathrm{N}=10, a=90, b=100$ (growth stage).

(a)

\begin{tabular}{cccc}
\hline Outcome variable & $\begin{array}{c}\text { Number of cases } \\
\text { with } r=0.25\end{array}$ & $\begin{array}{c}\text { Number of cases } \\
\text { with } q=0.25\end{array}$ & $\begin{array}{c}\text { Number of cases } \\
\text { with } g=0.05\end{array}$ \\
\hline Mean & 8 & 8 & 7 \\
Variance & 6 & 5 & $10 \#$ \\
Dominance & 5 & 8 & 10 \\
$\lambda=0.5$ & 5 & 8 & 10 \\
$\lambda=1.0$ & 5 & 8 & 10 \\
$\lambda=1.5$ & 5 & 6 & 10 \\
\hline
\end{tabular}

(b)

\begin{tabular}{cccc}
\hline Outcome variable & $\begin{array}{c}\text { Number of cases } \\
\text { with } r=0.25\end{array}$ & $\begin{array}{c}\text { Number of cases } \\
\text { with } q=0.25\end{array}$ & $\begin{array}{c}\text { Number of cases } \\
\text { with } g=0.05\end{array}$ \\
\hline Mean & 10 & 2 & 8 \\
Variance & 4 & 4 & $10 \#$ \\
Dominance & 8 & 4 & 10 \\
$\lambda=0.5$ & 8 & 4 & 10 \\
$\lambda=1.0$ & 5 & 4 & 10 \\
$\lambda=1.5$ & 4 & 3 & 10 \\
\hline
\end{tabular}

Legend: $\#=0.25$.

Table 5. Spearman rank correlations between the outcome variables for $N=5$ and $a=0.9$ $\& b=1.1$.

\begin{tabular}{|c|c|c|c|c|c|c|}
\hline \multicolumn{3}{|c|}{ Outcome } & \multirow[b]{2}{*}{ Dominance } & \multirow[b]{2}{*}{$\lambda=0.5$} & \multirow[b]{2}{*}{$\lambda=1.0$} & \multirow[b]{2}{*}{$\lambda=1.5$} \\
\hline Outcome & Mean & Variance & & & & \\
\hline Mean & 1.000 & 0.134 & 0.700 & 0.884 & 0.730 & 0.587 \\
\hline$p$-value & & 0.234 & 0.000 & 0.000 & 0.000 & 0.000 \\
\hline Variance & 0.134 & 1.000 & -0.545 & -0.274 & -0.508 & -0.662 \\
\hline$p$-value & 0.234 & & 0.000 & 0.013 & 0.000 & 0.000 \\
\hline Dominance & 0.700 & -0.545 & 1.000 & 0.940 & 0.988 & 0.976 \\
\hline$p$-value & 0.000 & 0.000 & & 0.000 & 0.000 & 0.000 \\
\hline$\lambda=0.5$ & 0.884 & -0.274 & 0.940 & 1.000 & 0.959 & 0.886 \\
\hline$p$-value & 0.000 & 0.013 & 0.000 & & 0.000 & 0.000 \\
\hline$\lambda=1.0$ & 0.730 & -0.508 & 0.988 & 0.959 & 1.000 & 0.977 \\
\hline$p$-value & 0.000 & 0.000 & 0.000 & 0.000 & & 0.000 \\
\hline$\lambda=1.5$ & 0.587 & -0.662 & 0.976 & 0.886 & 0.977 & 1.000 \\
\hline$p$-value & 0.000 & 0.000 & 0.000 & 0.000 & 0.000 & \\
\hline
\end{tabular}


Table 6. Spearman rank correlations between the parameters and the outcome variables for $N=5$ and $a=0.9 \& b=1.1$.

\begin{tabular}{ccccccc}
\hline \multicolumn{5}{c}{ Outcome } & \multicolumn{7}{c}{} \\
\hline Parameter & Mean & Variance & Dominance & $\lambda=0.5$ & $\lambda=1.0$ & $\lambda=1.5$ \\
\hline$r$ & 0.464 & 0.272 & 0.200 & 0.330 & 0.218 & 0.127 \\
$p$-value & 0.000 & 0.014 & 0.074 & 0.003 & 0.051 & 0.260 \\
$q$ & -0.796 & -0.353 & -0.368 & -0.587 & -0.404 & -0.254 \\
$p$-value & 0.000 & 0.001 & 0.001 & 0.000 & 0.000 & 0.022 \\
$g$ & -0.347 & 0.775 & -0.811 & -0.681 & -0.825 & -0.886 \\
$p$-value & 0.002 & 0.000 & 0.000 & 0.000 & 0.000 & 0.000 \\
$d$ & 0.023 & -0.283 & 0.259 & 0.139 & 0.198 & 0.247 \\
$p$-value & 0.837 & 0.011 & 0.020 & 0.216 & 0.077 & 0.026 \\
\hline
\end{tabular}

with the mean and the variance of $D C F_{t}$ but its correlation with the risk aversion outcomes significantly diminishes in $\lambda$. It also shows that $q$ and $g$ are strongly negatively correlated with the mean and the risk aversion outcomes. The variance of $\mathrm{DCF}_{\mathrm{t}}$ has a high positive correlation with $g$, which makes the correlation between $g$ and risk aversion outcomes correlate the stronger, the higher is $\lambda$. There are only relatively low correlations between $d$ and the outcome variables indicating a weak effect of the discount rate.

Appendix 1 shows that an increase in the risk level $(a=80$ and $b=120)$ does not remarkably change the cases with the extreme values for the outcome variables. The most remarkable effect is that the negative impact of $q$ on the risk aversion outcomes is here not as systematic as under lower risk circumstances. Moreover, Appendix 2 indicates that the positive rank correlations between the mean and these risk aversion outcome variables have significantly decreased. However, at the same time the negative correlation between the outcomes and the variance of $D C F_{t}$ has become clearly more significant. The rank correlations between dominance and the risk aversion outcomes with higher rates $\lambda(\lambda=1.0$ or 1.5) have also decreased. Appendix 3 shows that the significance of the rank correlations of the risk aversion outcomes to $r$ and $q$ have significantly decreased and even changed their sign. At the same time, the negative correlations between the risk aversion outcome variables (especially with lower $\lambda$ ) and $g$ have become more significant.

\subsection{Growth Stage}

Figure 2 shows the scatter diagram for the mean-variance relationship when the ten first years are used to calculate $D C F_{t}(N=10)$. There are a number of observations with a positive mean concentrated on the lower right corner of the diagram. Table 7 shows the extreme values of the outcome variables for the growth stage. There are only some systematic changes in the determinants of the extreme values of the outcome variables. Mainly, the highest values of the mean 


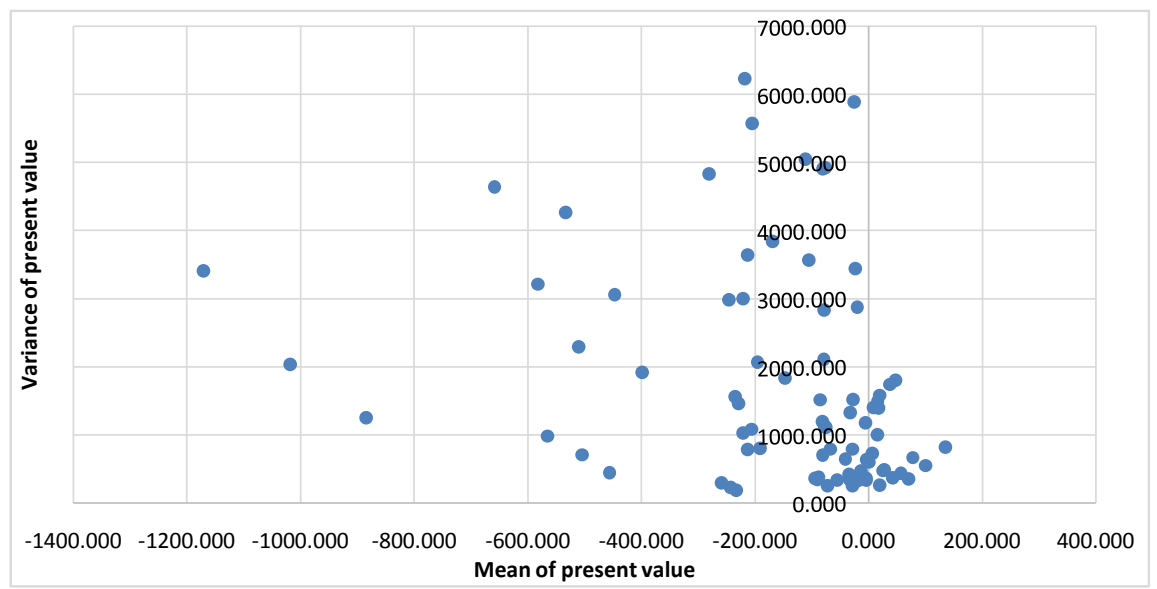

Figure 2. The relationship between the mean and the variance of DCF for $N=10$ and $a=$ $0.9 \& b=1.1$.

Table 7. Highest and lowest values of the outcome variables for $N=10$ and $a=0$.

\begin{tabular}{|c|c|c|c|c|c|c|}
\hline & \multicolumn{2}{|c|}{ Highest value } & \multicolumn{4}{|c|}{ Lowest value } \\
\hline & 1. & 2. & 3. & 1. & 2. & 3. \\
\hline Mean & 135.63 & 100.73 & 78.06 & -1171.44 & -1018.73 & -884.69 \\
\hline$r$ & 0.250 & 0.250 & 0.250 & 0.050 & 0.050 & 0.050 \\
\hline$q$ & 0.750 & 0.750 & 0.500 & 0.750 & 0.750 & 0.750 \\
\hline$g$ & 0.050 & 0.050 & 0.050 & 0.250 & 0.250 & 0.250 \\
\hline$d$ & 0.025 & 0.050 & 0.025 & 0.025 & 0.050 & 0.075 \\
\hline Variance & 6231.55 & 5889.77 & 5571.55 & 184.22 & 224.26 & 250.84 \\
\hline$r$ & 0.250 & 0.250 & 0.050 & 0.050 & 0.050 & 0.150 \\
\hline$q$ & 0.750 & 0.250 & 0.250 & 0.750 & 0.750 & 0.750 \\
\hline$g$ & 0.250 & 0.250 & 0.250 & 0.050 & 0.050 & 0.050 \\
\hline$d$ & 0.025 & 0.025 & 0.025 & 0.075 & 0.050 & 0.075 \\
\hline Dominance & 66 & 65 & 61 & 0 & 0 & 0 \\
\hline$r$ & 0.250 & 0.250 & 0.250 & 0.150 & 0.050 & 0.150 \\
\hline$q$ & 0.750 & 0.250 & 0.500 & 0.500 & 0.750 & 0.750 \\
\hline$g$ & 0.050 & 0.050 & 0.050 & 0.250 & 0.250 & 0.250 \\
\hline$d$ & 0.075 & 0.075 & 0.075 & 0.025 & 0.025 & 0.025 \\
\hline$\lambda=0.5$ & -17.39 & -36.02 & -45.90 & -2024.19 & -1818.04 & -1776.08 \\
\hline$r$ & 0.250 & 0.250 & 0.250 & 0.050 & 0.150 & 0.250 \\
\hline$q$ & 0.750 & 0.750 & 0.250 & 0.750 & 0.750 & 0.750 \\
\hline$g$ & 0.050 & 0.050 & 0.050 & 0.250 & 0.250 & 0.250 \\
\hline$d$ & 0.075 & 0.050 & 0.075 & 0.025 & 0.025 & 0.025 \\
\hline$\lambda=1.0$ & -105.81 & -111.68 & -142.06 & -3333.96 & -2991.01 & -2977.48 \\
\hline$r$ & 0.250 & 0.250 & 0.250 & 0.250 & 0.050 & 0.150 \\
\hline$q$ & 0.750 & 0.250 & 0.500 & 0.750 & 0.250 & 0.750 \\
\hline$g$ & 0.050 & 0.050 & 0.050 & 0.250 & 0.250 & 0.250 \\
\hline$d$ & 0.075 & 0.075 & 0.075 & 0.025 & 0.025 & 0.025 \\
\hline$\lambda=1.5$ & -177.45 & -194.24 & -217.60 & -4891.85 & -4442.68 & -4383.90 \\
\hline$r$ & 0.250 & 0.250 & 0.050 & 0.250 & 0.250 & 0.050 \\
\hline$q$ & 0.250 & 0.750 & 0.250 & 0.750 & 0.250 & 0.250 \\
\hline$g$ & 0.050 & 0.050 & 0.050 & 0.250 & 0.250 & 0.250 \\
\hline$d$ & 0.075 & 0.075 & 0.075 & 0.025 & 0.025 & 0.025 \\
\hline
\end{tabular}


DCF are now associated with high values of $q$ whereas in the launch stage they were associated with low ones. However, in the growth stage also the lowest values of the mean are resulted for high $q$. Panel 2 of Table 4 shows that TOP 10 for the mean DCF includes only two cases with the lowest value of $q(0.25)$. However, it includes ten cases with the highest value of $r(0.25)$ and eight cases with the lowest value of $g(0.05)$. TOP 10 for the other outcome variables only include 3 - 4 cases with the lowest value of $q(0.25)$ indicating that its effect is weak in the growth stage. Similarly as in the launch stage, TOP ten for other outcome variables than the mean includes all ten cases with the lowest value for $g(0.05)$ (except for the variance with ten cases with the highest value).

Consistently with the results for TOP 10, the Spearman rank correlations between the outcome variables are in this growth stage different as the correlations in the launch stage. Table 8 shows that the rank correlation of the mean with the variance is now negative and with the risk aversion outcome variables significantly lower than in the launch stage. However, the negative correlations between the variance and the outcome variables of risk aversion are significantly stronger. The risk aversion outcome variables also correlate more with each other than in the launch stage. Table 9 shows that the effect of $r$ on the mean and the dominance is now stronger being however insignificant on the risk aversion variables. Moreover, $q$ has a significant (negative) effect only on the mean whereas the rank correlations of $g$ with all outcome variables are very high. The effect of $g$ on the mean is almost as strong as that of $r$ but remarkably stronger on other outcome variables. Thus, longer time series no doubt strengthens the effect of growth on the outcome variables making its impact dominant.

Table 8. Spearman rank correlations between the outcome variables for $N=10$ and $a=$ $0.9 \& b=1.1$.

\begin{tabular}{|c|c|c|c|c|c|c|}
\hline & Outcome & & & & & \\
\hline Outcome & Mean & Variance & Dominance & $\lambda=0.5$ & $\lambda=1.0$ & $\lambda=1.5$ \\
\hline Mean & 1.000 & -0.356 & 0.817 & 0.726 & 0.614 & 0.551 \\
\hline$p$-value & & 0.001 & 0.000 & 0.000 & 0.000 & 0.000 \\
\hline Variance & -0.356 & 1.000 & -0.776 & -0.875 & -0.939 & -0.964 \\
\hline$p$-value & 0.001 & & 0.000 & 0.000 & 0.000 & 0.000 \\
\hline Dominance & 0.817 & -0.776 & 1.000 & 0.972 & 0.935 & 0.905 \\
\hline$p$-value & 0.000 & 0.000 & & 0.000 & 0.000 & 0.000 \\
\hline$\lambda=0.5$ & 0.726 & -0.875 & 0.972 & 1.000 & 0.983 & 0.964 \\
\hline$p$-value & 0.000 & 0.000 & 0.000 & & 0.000 & 0.000 \\
\hline$\lambda=1.0$ & 0.614 & -0.939 & 0.935 & 0.983 & 1.000 & 0.995 \\
\hline$p$-value & 0.000 & 0.000 & 0.000 & 0.000 & & 0.000 \\
\hline$\lambda=1.5$ & 0.551 & -0.964 & 0.905 & 0.964 & 0.995 & 1.000 \\
\hline$p$-value & 0.000 & 0.000 & 0.000 & 0.000 & 0.000 & \\
\hline
\end{tabular}


Table 9. Spearman rank correlations between the parameters and the outcome variables for $N=10$ and $\mathrm{a}=0.9 \& b=1.1$.

\begin{tabular}{|c|c|c|c|c|c|c|}
\hline \multicolumn{7}{|c|}{ Outcome } \\
\hline Parameter & Mean & Variance & Dominance & $\lambda=0.5$ & $\lambda=1.0$ & $\lambda=1.5$ \\
\hline$r$ & 0.658 & 0.164 & 0.298 & 0.186 & 0.069 & 0.006 \\
\hline$p$-value & 0.000 & 0.143 & 0.007 & 0.097 & 0.539 & 0.959 \\
\hline$q$ & -0.374 & -0.041 & -0.256 & -0.162 & -0.103 & -0.068 \\
\hline$p$-value & 0.001 & 0.714 & 0.021 & 0.148 & 0.361 & 0.547 \\
\hline$g$ & -0.544 & 0.925 & -0.841 & -0.923 & -0.941 & -0.943 \\
\hline$p$-value & 0.000 & 0.000 & 0.000 & 0.000 & 0.000 & 0.000 \\
\hline$d$ & 0.019 & -0.279 & 0.235 & 0.212 & 0.265 & 0.281 \\
\hline$p$-value & 0.868 & 0.012 & 0.034 & 0.057 & 0.017 & 0.011 \\
\hline
\end{tabular}

Appendix 4 presents the results for the growth stage with the longer time-series $(N=10)$ under higher risk circumstances $(a=80$ and $b=120)$. This appendix shows that, similarly as under the lower risk circumstances, an increase in the risk level does not significantly alter the cases with the extreme values of the outcome variables. Appendix 5 indicates that the rank correlations of the mean DCF to the risk aversion outcomes however have significantly decreased. The negative correlations between these risk aversion variables and the variance of DCF have strongly strengthened towards minus unity. Similarly, the correlations between the risk aversion variables have now increased close to unity. Appendix 6 indicates that the rank correlation of $r$ with the risk aversion outcome variables is in this stage negative but insignificant. Moreover, $q$ has a significant (negative) correlation only with the mean. The effect of $g$ on the outcome variables has stayed very strong. This effect (measured as a rank correlation) is negative except for the variance. The effect of $d$ on the outcome variables is similar as in the previous case and is only characterized by relatively lowrank correlations reflecting a weak impact.

\subsection{Empirical Evidence}

The findings presented above are based on a simplified mathematical model that is assumed to generate a cash flow series analyzed here using numerical experiments. The numerical results show that along the positive impact of IRR, also $g$ and $q$ have a strong negative effect on different outcomes based on DCF. The crucial question is whether these kinds of relationships are observable in reality. This question is assessed in this study using empirical data from Finnish startups. These data have been extracted from the ORBIS database of Bureau Van Dijk (BvD). The data were extracted under the restrictions that the firm must be Finnish, limited company, founded in the beginning of 2000 decade, and have successive financial statements available for at least 10 years. In all, financial 
statements from 5190 startups were extracted. The median of the founding year was 2005 while the youngest firm was founded in 2008 and the oldest firm in 2004. The average number of employees in the last available year was 10 whereas the median was only 3 . Therefore, the size distribution is skewed as it is in the population of Finnish startups.

In order to assess the effects of the parameters of the model, there stricted linear least squares (RLS) estimation method was applied to the nine-year time series of total expenditure and total revenue following equation (2) in the steady form. This estimation method followed the procedure described in Laitinen [14] that is not analytically repeated here. The estimation of the parameters proved to be a very challenging task due to sensitivity. First, the growth rate of total expenditure $g$ was estimated by the ordinary LS applying it to the logarithmic time series of expenditure and time index. Secondly, the parameters $r$ and $q$ were estimated using the Koyck transformation and setting a restriction in the equation to decrease the level of sensitivity [14]. In spite of the advanced estimation method, a large number of estimates proved to be inconsistent due to the non-steady nature of startup development. The consistency of estimates was improved limiting the values of $q$ to the interval from 0.15 to 0.85 . Then, after deleting observations with inconsistent estimates outside the interval, the final sample consisted of 2290 startups out of 5190 original firms.

The estimation period was characterized by the 2008 financial crisis that produced a significant economic shock to the global economy. This crisis first touched the U.S. financial sector in 2007, but the effects spread to several national economies, resulting in what has often been called the Great Recession. Thus, the economic development also in Finland was unstable and quite negative. Therefore, the median IRR or $r$ in the sample was only $6.3 \%$ while the median growth rate $g$ was as low as $3.6 \%$ and the median $q 0.37$. The present value of the cash flow DCF was directly calculated from the official financial statements (without using the theoretical model) discounting the difference between total revenue $R_{t}$ and total expenditure $E_{t}$ using $5.0 \%$ as a discount rate. Furthermore, the size effect on DCF was eliminated dividing DCF by total expenditure $\left(M_{0}\right)$ in the first available period.

The empirical results should be interpreted cautiously. It is clear that especially the exceptionally low values of $r$ and $g$ due to financial crisis period at least to some degree affect the results [24] [25]. However, alternative values of the discount rate applied to calculate DCF did not alter the conclusions. Table 10 presents the Spearman rank correlations between DCF, $r, q$, and $g$ calculated for the sample of 2290 startups. Empirical evidence strongly supports the findings got from the numerical experiments. DCF is strongly negatively correlated with the growth rate $g(-0.601)$ and positively with IRR or $r(0.506)$. The sign of the correlation between DCF and $q$ is negative $(-0.071)$ as it was found in the numerical experiments. The observed weak effect of the discount rate $d$ on DCF is also consistent with the results from the experiments. 
Table 10. Spearman rank correlations between DCF and the model parameters estimated from a sample of 2290 Finnish startups.

\begin{tabular}{ccccc}
\hline & DCF & $r$ & $q$ & $g$ \\
\hline DCF & 1.000 & 0.506 & -0.071 & -0.601 \\
& & 0.000 & 0.001 & 0.000 \\
$r$ & 0.506 & 1.000 & 0.051 & -0.154 \\
$p$-value & 0.000 & & 0.015 & 0.000 \\
$q$ & -0.071 & 0.051 & 1.000 & 0.217 \\
$p$-value & 0.001 & 0.015 & & 0.000 \\
$g$ & -0.601 & -0.154 & 0.217 & 1.000 \\
$p$-value & 0.000 & 0.000 & 0.000 & \\
\hline
\end{tabular}

\section{Concluding Remarks}

\subsection{Main Findings}

The importance of startups is significant for any economy investing on innovations and growth. The number of new startups is quite large. However, the survival rate of startups in the first five years is only about $45 \%$ - 55\% in U.S. and Europe [26] [27] [28]. Therefore, it is of importance for investors to understand the consequences of using alternative valuation methods in startups. For the economy, it is efficient to allocate scarce financial resources to startups, which show the highest profitability and growth. In this way, the resources of the economy are used in the most efficient way. The most popular valuation method used by startup investors is the discounted cash flow DCF. Therefore, this study concentrated on analyzing the consequences of using the discounted cash flow. However, the model used in this study also includes IRR and a proxy of the payback period. The purpose of the numerical experiments carried out here was to show what kinds of startups would most likely get finance if DCF in different forms was used as the main criterion. From the point of view of the economy, the most desirable conclusion would be that the use of DCF leads to a situation where the most profitable firms with a high growth rate are located at the top of ranking. The results got in this study do not give much support to these kinds of expectations.

Table 11 presents a summary of the main effects of the parameters on the outcome variables. The results of the study indicate that, in the launch stage, the short payback period proxy is the variable that most significantly affects the mean of DCF. Thus, startups that generate revenue very quickly after foundation such as retailing or service startups enjoy from a high mean. However, high technology firms with a long payback period are likely to suffer from this negative feature of DCF. The profitability of the startup in the form of IRR also affects the mean, which is a recommended feature of the mean. It is, however, not a recommended feature that the growth rate has a negative impact on the mean leading to that the use of the mean DCF as the criterion gives an advantage to 
Table 11. The main effects on the outcome variables under different circumstances.

\begin{tabular}{|c|c|c|c|c|c|c|}
\hline Circumstances & Mean & Variance & Dominance & $\lambda=0.5$ & $\lambda=1.0$ & $\lambda=1.5$ \\
\hline \multicolumn{7}{|c|}{ 1) Lower risk $(a=0.9 \& b=1.1)$} \\
\hline \multirow[t]{3}{*}{$\mathrm{N}=5$ (launch stage) } & 1) $-\mathrm{Pb}-$ period & 1) +Growth & 1) -Growth & 1) -Growth & 1) -Growth & 1) -Growth \\
\hline & 2) +IRR & 2) - $\mathrm{Pb}$-period & 2) - $\mathrm{Pb}$-period & 2) - $\mathrm{Pb}$-period & 2) - $\mathrm{Pb}$-period & \\
\hline & 3) -Growth & & & 3) + IRR & & \\
\hline \multirow[t]{3}{*}{$\mathrm{N}=10$ (growth stage) } & 1) +IRR & 1) +Growth & 1) -Growth & 1) -Growth & 1) -Growth & 1) -Growth \\
\hline & 2) -Growth & & 2) +IRR & & & \\
\hline & 3) $-\mathrm{Pb}$-period & & & & & \\
\hline \multicolumn{7}{|c|}{ 2) Higher risk ( $a=0.8 \& b=1.2)$} \\
\hline \multirow[t]{3}{*}{$\mathrm{N}=5$ (launch stage) } & 1) $-\mathrm{Pb}$-period & 1) +Growth & 1) -Growth & 1) -Growth & 1) -Growth & 1) -Growth \\
\hline & 2). + IRR & 2) - $\mathrm{Pb}$-period & 2) $-\mathrm{Pb}$-period & & & \\
\hline & 3) -Growth & & & & & \\
\hline \multirow[t]{3}{*}{$\mathrm{N}=10$ (growth stage) } & 1) +IRR & 1. +Growth & 1) -Growth & 1) -Growth & 1) -Growth & 1) -Growth \\
\hline & 2) -Growth & & 2) $+\mathrm{IRR}$ & & & \\
\hline & 3) $-\mathrm{Pb}$-period & & & & & \\
\hline
\end{tabular}

startups with a low growth rate. In the passage of time, the impact of IRR becomes stronger and for the growth stage, its impact is the most significant. This result indicates that for a longer time series of a startup, the mean DCF may give reasonable results. However, also in this case where the time series is longer, both the payback period proxy and the growth rate have a remarkable negative effect on the mean DCF.

For the launch stage, high growth rate and short payback period significantly tend to increase the variance of DCF. When the growth stage is considered, the positive effect of growth will become dominant. If DCF is used to find out dominant startups with respect to the mean and variance, the negative effects of the growth rate and the payback period proxy are the only significant determinants in the launch stage. Again, when the growth stage is considered the effect of the payback period becomes insignificant and IRR makes a positive effect on the dominance. However, the negative effect of the growth rate is still the strongest impact. When the expected utility of the investor is to be maximized, the rate of risk aversion plays an important role. If the rate is low, the expected utility is determined by the negative impact of growth and payback period but also by the positive impact of IRR. When the rate of risk aversion increases, the effect of IRR will firstly vanish and finally, for higher rates, the negative effect of growth is the only significant determinant of the expected utility. However, for the growth stage and for riskier circumstances this expected utility is only determined by growth.

The methodology of this study was primarily numerical experimentation based on a theoretical model, which may question the relevance of the results 
from the point of view of practice. Therefore, data from a sample of Finnish startups were extracted and used to assess the validity and thus the practical relevance of the conclusions. These final data used in the empirical analysis were extracted from 2290 startups. The estimates of IRR and the payback period proxy proved to be very sensitive, which lead to drop a large number of observations from the initial sample. However, the rank correlations calculated for the final sample clearly supported the experimental results: DCF was positively correlated with IRR but negatively with the growth rate and the payback period proxy. Thus, empirical evidence supports the conclusions that DCF is sensitive to IRR but also to growth and payback period proxy in the way, which may lead investors to invest on startups, characterized by a low growth rate and a short payback period.

\subsection{Summary}

The findings of this study have a special value since valuation methods based on DCF are both recommended by previous studies [7] and widely used by investors in startups [8] [9] [10]. In its basic form, DCF includes a number of difficult tasks to be solved such as to estimate the expected future cash flows and the terminal value, and to choose the appropriate risk-adjusted rate that quantifies the risk inherent to the investment. The problems associated with these difficulties are widely analyzed in prior research [7] [15] and they are therefore excluded from the present study. Unlike prior studies, this approach concentrated on the outcomes followed from adopting DCF as a startup valuation method. Therefore, the findings of this study are novel and important to investors and other stakeholders. If the investment policy gives recommendations to finance rapidly growing high tech firms with a long payback period, investors should be cautious when using DCF as the primary investment criterion. Technically, the findings of this study indicate that DCF may favor slowly growing firms with a short payback period at the expense of fast growing high tech firms. Furthermore, the effect of IRR on DCF is weak especially in the launch stage. However, the significance of IRR will rise when the time series become longer approaching the growth stage. Thus, the results indicate that DCF may include features that are not always recommendable for the stakeholders investing on startups.

This study however includes limitations that should be taken into account when considering the findings and outlining future research. Firstly, the mathematical model used here is a simplification based on a constant growth rate and other constant parameters (IRR and revenue lag). In future research, more advanced models with more realistic assumptions should be developed. The present approach also neglects the terminal value referring to future growth potential. Models that include the impact of the terminal value should be constructed in future studies to investigate DCF in more realistic circumstances. Moreover, the methodology employed here is based on numerical experiments using three representative levels of values for each parameter. In future, more advanced statistical methods should be used. This study employed also empirical 
evidence to assess the validity of numerical experiments. In future research, larger empirical data and advanced analysis methods should be utilized in investigations. However, it is the hope that the results anyway are fruitful and give inspirations to continue future scientific research on DCF following these lines outlined in this study.

\section{Conflicts of Interest}

The author declares no conflicts of interest regarding the publication of this paper.

\section{References}

[1] Davila, A., Foster, G., He, X. and Shimizu, C. (2015) The Rise and Fall of Startups: Creation and Destruction of Revenue and Jobs by Young Companies. Australian Journal of Management, 40, 6-35. https://doi.org/10.1177/0312896214525793

[2] Huynh, K.P., Petrunia, R.J. and Voia, M. (2012) Duration of New Firms: The Role of Startup Financial Conditions, Industry and Aggregate Factors. Structural Change and Economic Dynamics, 23, 354-362. https://doi.org/10.1016/j.strueco.2012.03.008

[3] Zingales, L. (1998) Survival of the Fittest or the Fattest? Exit and Financing in the Trucking Industry. Journal of Finance, 53, 905-938.

https://doi.org/10.1111/0022-1082.00039

[4] Almeida, H., Campello, M. and Weisbach, M.S. (2004) The Cash Flow Sensitivity of Cash. Journal of Finance, 59, 1777-1804. https://doi.org/10.1111/j.1540-6261.2004.00679.x

[5] Alti, A. (2003) How Sensitive Is Investment to Cash Flow When Financing Is Frictionless? The Journal of Finance, 58, 707-722.

https://doi.org/10.1111/1540-6261.00542

[6] Ak, B.K., Dechow, P.M., Sun, Y. and Wang, A.Y. (2013) The Use of Financial Ratio Models to Help Investors Predict and Interpret Significant Corporate Events. Australian Journal of Management, 38, 553-598.

https://doi.org/10.1177/0312896213510714

[7] Reverte, C., Sánchez-Hernández, M.M. and Rojo-Ramírez, A. (2016) The Profile of Venture Capital Investments: The European Context. International Journal Business and Globalisation, 17, 83-110. https://doi.org/10.1504/IJBG.2016.077568

[8] Dittmann, I., Maug, E. and Kemper, J. (2004) How Fundamental Are Fundamental Values? Valuation Methods and Their Impact on the Performance of German Venture Capitalists. European Financial Management, 10, 609-638.

https://doi.org/10.1111/j.1354-7798.2004.00268.x

[9] Pintado, T.R., García, D. and Van Auken, H. (2007) Venture Capital in Spain by Stage of Development. Journal of Small Business Management, 45, 68-88. https://doi.org/10.1111/j.1540-627X.2007.00199.x

[10] Sander, P. and Koomägi, M. (2007) Valuation of Private Companies by Estonian Private Equity and Venture Capitalists. Baltic Journal of Management, 2, 6-19. https://doi.org/10.1108/17465260710720219

[11] Garnsey, E., Stam, E. and Heffernan, P. (2006) New Firm Growth: Exploring Processes and Paths. Industry and Innovation, 13, 1-20. https://doi.org/10.1080/13662710500513367

[12] Reid, G.C. (2003) Trajectories of Small Business Financial Structure. Small Business 
Economics, 20, 273-285. https://doi.org/10.1023/A:1022915308274

[13] Coad, A., Frankish, J., Roberts, R.G. and Storey, D.J. (2013) Growth Paths and Survival Chances: An Application of Gambler's Ruin Theory. Journal of Business Venturing, 28, 615-632. https://doi.org/10.1016/j.jbusvent.2012.06.002

[14] Laitinen, E.K. (2017) Profitability Ratios in the Early Stages of a Startup. The Journal of Entrepreneurial Finance, 19, 1-28.

[15] Jennergren, L.P. (2008) Continuing Value in Firm Valuation by the Discounted Cash Flow Model. European Journal of Operational Research, 185, 1548-1563. https://doi.org/10.1016/j.ejor.2006.08.012

[16] Feenstra, D.W. and Wang, H. (2000) Economic and Accounting Rates of Return. Working Paper, University of Groningen, Research Institute SOM. SOM-Theme E Financial Markets and Institutions. E42.

[17] Laitinen, E.K. (2006) Financial Statement Data in Assessing the Potential of a Technology Firm: The Case of Nokia. International Review of Financial Analysis, 15, 256-286. https://doi.org/10.1016/j.irfa.2005.03.001

[18] Laitinen, E.K. (2012) Profitability, Growth, and Different Flow Ratio Concepts: Implications for Failing Firms. Review of Economics and Finance, 2, 112-130.

[19] Brief, R.P. (2013) Estimating the Economic Rate of Return from Accounting Data (RLE Accounting). Volume 16, Taylor and Francis, Routledge, Abingdon-on-Thames. https://doi.org/10.4324/9781315886404

[20] Gilbert, B.A., McDougall, P.P. and Audretsch, D.B. (2006) New Venture Growth: A Review and Extension. Journal of Management, 32, 926-950. https://doi.org/10.1177/0149206306293860

[21] Geroski, P.A. (2000) Models of Technology Diffusion. Research Policy, 29, 603-625. https://doi.org/10.1016/S0048-7333(99)00092-X

[22] Gandelman, N. and Hernández-Murillo, R. (2014) Risk Aversion at the Country Level. Working Paper 2014-005B, Federal Reserve Bank of St. Louis, St. Louis. http://research.stlouisfed.org/wp/2014/2014-005.pdf https://doi.org/10.20955/wp.2014.005

[23] Pirjetä, A. (2009) Evaluation of Executive Stock Options in Continuous and Discrete Time. Acta Universitatis Oeconomicae Helsingiensis. A-349. Doctoral Thesis, Aalto University, Helsinki.

[24] Devece, C., Peris-Ortiz, M. and Rueda-Armengot, C. (2016) Entrepreneurship during Economic Crisis: Success Factors and Paths to Failure. Journal of Business Research, 69, 5366-5370. https://doi.org/10.1016/j.jbusres.2016.04.139

[25] Sedlacek, P. and Sterk, V. (2017) The Growth Potential of Startups over the Business Cycle. American Economic Review, 107, 3182-3210. https://doi.org/10.1257/aer.20141280

[26] U.S. Bureau of Labor Statistics (2016) Business Employment Dynamics. Entrepreneurship and the U.S. Economy.

[27] Eurostat (2016) Business Demography by Size Class (from 2004 Onwards, NACE Rev. 2).

[28] Perry, A., Rahim, E. and Davis, B. (2018) Startup Success Trends in Small Business Beyond Five-Years: A Qualitative Research Study. Journal of Sustainable Entrepreneurship and Corporate Social Responsibility, 3, 1-16. https://doi.org/10.4018/IJSECSR.2018010101 
Appendix 1. Highest and lowest values of the outcome variables for $N=5$ and $a=0.8 \&$ $b=1.2$.

\begin{tabular}{|c|c|c|c|c|c|c|}
\hline & \multicolumn{2}{|c|}{ Highest value } & \multicolumn{4}{|c|}{ Lowest value } \\
\hline & 1. & 2. & 3. & 1. & 2. & 3. \\
\hline Mean & 0.03 & -1.17 & -4.26 & -436.25 & -408.85 & -381.09 \\
\hline$r$ & 0.250 & 0.250 & 0.250 & 0.050 & 0.050 & 0.050 \\
\hline$q$ & 0.250 & 0.250 & 0.250 & 0.750 & 0.750 & 0.750 \\
\hline$g$ & 0.050 & 0.050 & 0.050 & 0.250 & 0.250 & 0.250 \\
\hline$d$ & 0.025 & 0.050 & 0.075 & 0.025 & 0.050 & 0.075 \\
\hline Variance & 2671.70 & 2646.72 & 2586.85 & 302.42 & 340.19 & 491.24 \\
\hline$r$ & 0.250 & 0.250 & 0.250 & 0.050 & 0.050 & 0.050 \\
\hline$q$ & 0.500 & 0.250 & 0.750 & 0.750 & 0.750 & 0.750 \\
\hline$g$ & 0.250 & 0.250 & 0.250 & 0.050 & 0.050 & 0.150 \\
\hline$d$ & 0.075 & 0.025 & 0.025 & 0.075 & 0.050 & 0.075 \\
\hline Dominance & 62 & 59 & 55 & 0 & 0 & 0 \\
\hline$r$ & 0.250 & 0.250 & 0.150 & 0.050 & 0.050 & 0.150 \\
\hline$q$ & 0.500 & 0.250 & 0.250 & 0.500 & 0.750 & 0.750 \\
\hline$g$ & 0.050 & 0.050 & 0.050 & 0.250 & 0.250 & 0.250 \\
\hline$d$ & 0.075 & 0.050 & 0.075 & 0.025 & 0.025 & 0.025 \\
\hline$\lambda=\mathbf{0 . 5}$ & -172.96 & -188.72 & -191.04 & -832.28 & -745.25 & -740.39 \\
\hline$r$ & 0.250 & 0.150 & 0.250 & 0.250 & 0.250 & 0.150 \\
\hline$q$ & 0.500 & 0.250 & 0.250 & 0.750 & 0.500 & 0.500 \\
\hline$g$ & 0.050 & 0.050 & 0.050 & 0.250 & 0.250 & 0.250 \\
\hline$d$ & 0.075 & 0.075 & 0.050 & 0.025 & 0.075 & 0.025 \\
\hline$\lambda=1.0$ & -328.47 & -350.10 & -358.68 & -1478.99 & -1413.17 & -1349.11 \\
\hline$r$ & 0.250 & 0.050 & 0.050 & 0.250 & 0.250 & 0.250 \\
\hline$q$ & 0.500 & 0.250 & 0.750 & 0.750 & 0.500 & 0.250 \\
\hline$g$ & 0.050 & 0.050 & 0.050 & 0.250 & 0.250 & 0.250 \\
\hline$d$ & 0.075 & 0.075 & 0.075 & 0.025 & 0.075 & 0.025 \\
\hline$\lambda=1.5$ & -434.29 & -469.90 & -483.99 & -2125.70 & -2081.10 & -2010.79 \\
\hline$r$ & 0.050 & 0.050 & 0.250 & 0.250 & 0.250 & 0.250 \\
\hline$q$ & 0.750 & 0.750 & 0.500 & 0.750 & 0.500 & 0.250 \\
\hline$g$ & 0.050 & 0.050 & 0.050 & 0.250 & 0.250 & 0.250 \\
\hline$d$ & 0.075 & 0.050 & 0.075 & 0.025 & 0.075 & 0.025 \\
\hline
\end{tabular}


Appendix 2. Spearman rank correlations between the outcome variables for $N=5$ and $a$ $=0.8 \& b=1.2$.

\begin{tabular}{|c|c|c|c|c|c|c|}
\hline \multicolumn{7}{|c|}{ Outcome } \\
\hline Outcome & Mean & Variance & Dominance & $\lambda=0.5$ & $\lambda=1.0$ & $\lambda=1.5$ \\
\hline Mean & 1.000 & 0.121 & 0.714 & 0.494 & 0.235 & 0.131 \\
\hline$p$-value & & 0.282 & 0.000 & 0.000 & 0.035 & 0.244 \\
\hline Variance & 0.121 & 1.000 & -0.537 & -0.762 & -0.915 & -0.955 \\
\hline$p$-value & 0.282 & & 0.000 & 0.000 & 0.000 & 0.000 \\
\hline Dominance & 0.714 & -0.537 & 1.000 & 0.941 & 0.807 & 0.738 \\
\hline$p$-value & 0.000 & 0.000 & & 0.000 & 0.000 & 0.000 \\
\hline$\lambda=0.5$ & 0.494 & -0.762 & 0.941 & 1.000 & 0.951 & 0.910 \\
\hline$p$-value & 0.000 & 0.000 & 0.000 & & 0.000 & 0.000 \\
\hline$\lambda=1.0$ & 0.235 & -0.915 & 0.807 & 0.951 & 1.000 & 0.992 \\
\hline$p$-value & 0.035 & 0.000 & 0.000 & 0.000 & & 0.000 \\
\hline$\lambda=1.5$ & 0.131 & -0.955 & 0.738 & 0.910 & 0.992 & 1.000 \\
\hline$p$-value & 0.244 & 0.000 & 0.000 & 0.000 & 0.000 & \\
\hline
\end{tabular}

Appendix 3. Spearman rank correlations between the parameters and the outcome variables for $N=5$ and $a=0.8 \& b=1.2$.

\begin{tabular}{|c|c|c|c|c|c|c|}
\hline \multicolumn{7}{|c|}{ Outcome } \\
\hline Parameter & Mean & Variance & Dominance & $\lambda=0.5$ & $\lambda=1.0$ & $\lambda=1.5$ \\
\hline$r$ & 0.459 & 0.288 & 0.158 & 0.038 & -0.112 & -0.166 \\
\hline$p$-value & 0.000 & 0.009 & 0.160 & 0.735 & 0.320 & 0.140 \\
\hline$q$ & -0.798 & -0.339 & -0.405 & -0.169 & 0.056 & 0.142 \\
\hline$p$-value & 0.000 & 0.002 & 0.000 & 0.132 & 0.618 & 0.207 \\
\hline$g$ & -0.350 & 0.780 & -0.808 & -0.918 & -0.913 & -0.891 \\
\hline$p$-value & 0.001 & 0.000 & 0.000 & 0.000 & 0.000 & 0.000 \\
\hline$d$ & 0.019 & -0.244 & 0.217 & 0.215 & 0.247 & 0.254 \\
\hline$p$-value & 0.868 & 0.028 & 0.052 & 0.054 & 0.026 & 0.022 \\
\hline
\end{tabular}


Appendix 4. Highest and lowest values of the outcome variables for $N=10$ and $a=0.8 \&$ $b=1.2$.

\begin{tabular}{|c|c|c|c|c|c|c|}
\hline & \multicolumn{2}{|c|}{ Highest value } & \multicolumn{4}{|c|}{ Lowest value } \\
\hline & 1. & 2. & 3. & 1. & 2. & 3. \\
\hline Mean & 134.46 & 99.46 & 72.58 & -1180.56 & -1009.11 & -878.88 \\
\hline$r$ & 0.250 & 0.250 & 0.250 & 0.050 & 0.050 & 0.050 \\
\hline$q$ & 0.750 & 0.750 & 0.500 & 0.750 & 0.750 & 0.750 \\
\hline$g$ & 0.050 & 0.050 & 0.050 & 0.250 & 0.250 & 0.250 \\
\hline$d$ & 0.025 & 0.050 & 0.025 & 0.025 & 0.050 & 0.075 \\
\hline Variance & $25,872.33$ & $25,070.99$ & $23,257.05$ & 752.37 & 923.02 & 1072.80 \\
\hline$r$ & 0.250 & 0.250 & 0.250 & 0.050 & 0.050 & 0.150 \\
\hline$q$ & 0.250 & 0.750 & 0.500 & 0.750 & 0.500 & 0.750 \\
\hline$g$ & 0.250 & 0.250 & 0.250 & 0.050 & 0.050 & 0.050 \\
\hline$d$ & 0.025 & 0.025 & 0.025 & 0.075 & 0.075 & 0.075 \\
\hline Dominance & 67 & 65 & 65 & 0 & 0 & 0 \\
\hline$r$ & 0.250 & 0.250 & 0.250 & 0.050 & 0.250 & 0.050 \\
\hline$q$ & 0.250 & 0.750 & 0.500 & 0.250 & 0.250 & 0.500 \\
\hline$g$ & 0.050 & 0.050 & 0.050 & 0.250 & 0.250 & 0.250 \\
\hline$d$ & 0.075 & 0.075 & 0.075 & 0.025 & 0.025 & 0.025 \\
\hline$\lambda=0.5$ & -248.82 & -297.08 & -298.68 & -6483.13 & -6443.79 & -5865.26 \\
\hline$r$ & 0.250 & 0.150 & 0.250 & 0.250 & 0.250 & 0.250 \\
\hline$q$ & 0.250 & 0.250 & 0.500 & 0.250 & 0.750 & 0.500 \\
\hline$g$ & 0.050 & 0.050 & 0.050 & 0.250 & 0.250 & 0.250 \\
\hline$d$ & 0.075 & 0.075 & 0.075 & 0.025 & 0.025 & 0.025 \\
\hline$\lambda=1.0$ & -517.90 & -547.31 & -591.75 & -12951.21 & -12711.54 & -11679.52 \\
\hline$r$ & 0.250 & 0.050 & 0.150 & 0.250 & 0.250 & 0.250 \\
\hline$q$ & 0.250 & 0.500 & 0.250 & 0.250 & 0.750 & 0.500 \\
\hline$g$ & 0.050 & 0.050 & 0.050 & 0.250 & 0.250 & 0.250 \\
\hline$d$ & 0.075 & 0.075 & 0.075 & 0.025 & 0.025 & 0.025 \\
\hline$\lambda=1.5$ & -778.06 & -786.97 & -793.61 & -19419.29 & -18979.29 & -17493.78 \\
\hline$r$ & 0.050 & 0.250 & 0.050 & 0.250 & 0.250 & 0.250 \\
\hline$q$ & 0.500 & 0.250 & 0.750 & 0.250 & 0.750 & 0.500 \\
\hline$g$ & 0.050 & 0.050 & 0.050 & 0.250 & 0.250 & 0.250 \\
\hline$d$ & 0.075 & 0.075 & 0.075 & 0.025 & 0.025 & 0.025 \\
\hline
\end{tabular}


Appendix 5. Spearman rank correlations between the outcome variables for $N=10$ and $a$ $=0.8 \& b=1.2$.

\begin{tabular}{|c|c|c|c|c|c|c|}
\hline \multicolumn{7}{|c|}{ Outcome } \\
\hline Outcome & Mean & Variance & Dominance & $\lambda=0.5$ & $\Lambda=1.0$ & $\lambda=1.5$ \\
\hline Mean & 1.000 & -0.358 & 0.806 & 0.525 & 0.436 & 0.408 \\
\hline$p$-value & & 0.001 & 0.000 & 0.000 & 0.000 & 0.000 \\
\hline Variance & -0.358 & 1.000 & -0.786 & -0.973 & -0.994 & -0.996 \\
\hline$p$-value & 0.001 & & 0.000 & 0.000 & 0.000 & 0.000 \\
\hline Dominance & 0.806 & -0.786 & 1.000 & 0.894 & 0.840 & 0.822 \\
\hline$p$-value & 0.000 & 0.000 & & 0.000 & 0.000 & 0.000 \\
\hline$\lambda=0.5$ & 0.525 & -0.973 & 0.894 & 1.000 & 0.992 & 0.987 \\
\hline$p$-value & 0.000 & 0.000 & 0.000 & & 0.000 & 0.000 \\
\hline$\lambda=1.0$ & 0.436 & -0.994 & 0.840 & 0.992 & 1.000 & 0.999 \\
\hline$p$-value & 0.000 & 0.000 & 0.000 & 0.000 & & 0.000 \\
\hline$\lambda=1.5$ & 0.408 & -0.996 & 0.822 & 0.987 & 0.999 & 1.000 \\
\hline$p$-value & 0.000 & 0.000 & 0.000 & 0.000 & 0.000 & \\
\hline
\end{tabular}

Appendix 6. Spearman rank correlations between the parameters and the outcome variables for $N=10$ and $a=0.8 \& b=1.2$.

\begin{tabular}{|c|c|c|c|c|c|c|}
\hline \multicolumn{7}{|c|}{ Outcome } \\
\hline Parameter & Mean & Variance & Dominance & $\lambda=0.5$ & $\lambda=1.0$ & $\lambda=1.5$ \\
\hline$r$ & 0.659 & 0.149 & 0.296 & -0.002 & -0.082 & -0.108 \\
\hline$p$-value & 0.000 & 0.183 & 0.007 & 0.986 & 0.466 & 0.337 \\
\hline$q$ & -0.376 & -0.087 & -0.215 & -0.003 & 0.045 & 0.060 \\
\hline$p$-value & 0.001 & 0.438 & 0.054 & 0.977 & 0.688 & 0.598 \\
\hline$g$ & -0.544 & 0.931 & -0.852 & -0.943 & -0.941 & -0.940 \\
\hline$p$-value & 0.000 & 0.000 & 0.000 & 0.000 & 0.000 & 0.000 \\
\hline$d$ & 0.013 & -0.281 & 0.230 & 0.300 & 0.297 & 0.290 \\
\hline$p$-value & 0.909 & 0.011 & 0.039 & 0.007 & 0.007 & 0.009 \\
\hline
\end{tabular}

